\title{
Effect of Nanoparticles Reinforced Adhesive Layers on Microleakage of Tooth Restorations
}

\author{
Mohamed I. Ebrahim1, Mohamed Ashour Ahmed', Nayef H. Felemban ${ }^{3}$ \\ ${ }^{1}$ Department of Restorative Dentistry, Faculty of Dentistry, Taif University, Taif, Saudi Arabia \\ ${ }^{2}$ Department of Prosthodontics, Faculty of Dentistry, Taif University, Taif, Saudi Arabia \\ ${ }^{3}$ Department of Orthodontics, Faculty of Dentistry, Taif University, Taif, Saudi Arabia \\ Email:m.ismail@tudent.org,m.ashour@tudent.org,nfelemban@tudent.edu.sa
}

Received 26 May 2016; accepted 13 June 2016; published 16 June 2016

Copyright (C) 2016 by authors and Scientific Research Publishing Inc.

This work is licensed under the Creative Commons Attribution International License (CC BY). http://creativecommons.org/licenses/by/4.0/

(c) (i) Open Access

\begin{abstract}
Adhesive layer is an essential part of tooth colored restorations which play an important role in decreasing the microleakage between the tooth and restoration material after polymerization shrinkage. The purpose of this study was to evaluate the effect of deferent adhesive system of bonding agent on microleakage of nanocomposite resin in class II cavities. Two different types of adhesive systems: universal adhesive (ExciTE) and a newly developed adhesive (Nano-Bond) and one type of light-cured resin restorative material (nanocomposite resin) were used in this study. These adhesives were applied to prepared tooth cavities by either manufactures' instructions or by an experimental method (single or double application). Nanocomposite resin was then placed and light-cured for 40 seconds. Teeth were subjected to 500 thermal cycles between $5^{\circ} \mathrm{C}$ and $55^{\circ} \mathrm{C}$ and were immersed in $3 \%$ methylene blue solution for 24 hours; microleakage was observed microscopically. The data were analyzed by a two-way ANOVA. For comparison between groups, Tukey's post-hoc test was used. Nanoparticles reinforced adhesive system shows low microleakage in compare with universal adhesive system, and application of two adhesive layers also can decrease the microleakage. The ability of stress absorption by adhesive layer after polymerization shrinkage of restoration material will reduce the microleakage.
\end{abstract}

\section{Keywords}

Adhesive Layer, Tooth Colored Restorations, Nanoparticles, Microleakage

\section{Introduction}

A major shortcoming of light-cured composite resin is polymerization shrinkage. This shrinkage produces con-

How to cite this paper: Ebrahim, M.I., Ahmed, M.A. and Felemban, N.H. (2016) Effect of Nanoparticles Reinforced Adhesive Layers on Microleakage of Tooth Restorations. World Journal of Nano Science and Engineering, 6, 64-69. 
traction stress in a confined structure such as tooth cavity [1]. The contraction stress in resin composite plays an important role in marginal adaptation [2]. When the stress generated by the polymerization shrinkage exceeds the bond strength of adhesive resin to cavity walls and floor, a contraction gap of microleakage is formed [3] [4]. The linear shrinkage of microfilled composites ranged from $2 \%-3 \%$ after curing. Hybrid composites and micro-hybrid composite shrank from $0.6 \%-1.4 \%$ [5]. Such shrinkage caused microleakage, a well-known effect of contraction gaps on the interface of resin and tooth. Saliva, fluid, food residue, and microorganism strapped in the gaps lead to decayed teeth and damaged enamel which is a major problem in current restorative and esthetic dentistry so as to provide a material with high mechanical properties and low polymerization shrinkage. It was anticipated that composites with epoxy resin and nanosilica filler could fulfill these requirements [6] [7].

There have been many efforts at reducing the polymerization shrinkage in resin composites. One approach is through control of components of the composite itself such as the amount and type of matrix resin [8], the filler level [9], the curing chemistry [10], the initiator level [11] and the addition of non-bonded micro-filler particles [12]. The other approach is performed technically and includes a modified application technique [13] [14], the sandwich restoration with glass ionomer [15], the use of resin inlay [16], and controls the restoration rate by altering light energy [17] [18].

One practical approach to reducing the effects of composite contractions is to place a flexible and low-viscosity intermediate layer of a bond agent or a lining material between the composite and cavity walls [19] [20]. This layer acts as an elastic buffer at the resin-dentin interface and gives the total restoration the flexibility required to compensate for the part of the polymerization contraction. As a result, the adhesive bond will remain intact and marginal integrity will be preserved. This observation supports the stress-absorbing theory [21] [22]. Such stress can also be reduced significantly by a relatively thin layer of Scotch bond ${ }^{\mathrm{TM}}$ Multi-purpose adhesive and additional adhesive layers in the marginal area to reduce the overall degree of microleakage [20].

The purpose of this study was to evaluate the effect of deferent adhesive system of bonding agent on microleakage of nanocomposite resin in class II cavities.

\section{Material and Methods}

Two different types of adhesive available systems, ExciTE (Ivoclar, Vivadent, Schaan, Liechtenstein, Swiss, lot \#K41832) and Nano-Bond adhesives (Pentron Clinical Technologies, USA, lot \#183421) and one type of nanofilled composite (Artiste Nanocomposite, Pentron Clinical Technologies LLC, USA, lot \#182066-185215) were used in this study. ExciTE is a fourth-generation universal adhesive system and Nano-Bond is fourth-generation newly developed adhesive system.

Twenty freshly extracted caries-free human molar teeth were collected for the purpose of this study. The teeth were cleaned by an ultrasonic scaler and stored in distilled water at $37^{\circ} \mathrm{C}$ before testing.

Standardization class II cavities were prepared in the selected teeth. Cavities were prepared with 330 carbide burs at high speed with air-water coolant. The buccoligual width was $2 \mathrm{~mm}$ and $1.5 \mathrm{~mm}$ deep. The proximal boxes were prepared with No. 557 carbide burs. The proximal box margins were placed $2 \mathrm{~mm}$ above the cementoenamel junction. The depth of the box from the cavosurface margin to the axial wall was almost $2 \mathrm{~mm}$ and the occlusal was almost $4 \mathrm{~mm}$. The interproximal walls, floor, and marginal ridge area were beveled to approximately $1 \mathrm{~mm}$ long with No. 7901 carbide burs.

The prepared teeth were divided into two main groups (of 10 each) according to the type of adhesive system. Group A: ExciTE adhesive and Group B: Nano-Bond adhesive system. Each group was further subdivided into two subgroups (of five each) according to the layers of the adhesive system. Subgroup 1 (A1 \& B1): one layer of adhesive systems and subgroup 2 (A2 \& B2): two layers of adhesive systems.

The cavity of each tooth was acid etched using $37 \%$ phosphoric acid gel for 15 seconds. Then the teeth were rinsed with water spray and dried with oil-free stream for five seconds. The adhesives were applied on the cavities by either the manufactures' instructions or by an experimental method (single or double application). The adhesives were applied to the entire surface of the cavity and air thinned for 15 seconds. A gentle stream of dry air was applied to disperse the material into a thin, uniform, shiny appearing surface. The adhesive was then light-cured for 10 seconds with light emitting diodes (LED). Specimens with thick adhesive layers were produced by the application of one additional coat of adhesive. Additional coats were applied only to the marginal areas of the cavity to avoid pooling. Each layer was light-cured separately for 10 seconds.

Cavities were then filled with nanofilled composite. Resin composite was placed in two separately light-cured increments; each increment was light-cured for 40 seconds with the tip as close to the surface as possible. Cur- 
ing radiometer equipment was used to ensure steady light intensity throughout the polymerization of all specimens. All restorations were finished and polished with a set of solfex discs (3 M Company, St. Paul, MN, USA).

Teeth were prepared for microleakage evaluation by sealing the root apices with sticky wax. All other surfaces, except the restorations and $1 \mathrm{~mm}$ from the margins, were coated with two layers of nail varnish to avoid dye penetration. Teeth were stored in distilled water for 48 hours and then subjected to 500 thermal cycles between $5^{\circ} \mathrm{C}$ and $55^{\circ} \mathrm{C}$ water baths.

Dwell time was one minute with a 10 -second transit time between baths. After thermocycling, teeth were immersed in a 3\% methylene blue solution for 24 hours. Subsequently, all teeth were sectioned into two halfmesiodistally sections with a low-speed diamond disc ${ }^{*}$ under water coolant.

Dye penetration was measured under a stereomicroscope (Olympus SZ-PT-Japan) at 10x magnifications. Linear dye penetration (in microns) of each specimen in different groups was automatically calculated used the image analysis software (Image Ware, Image J 1.3lb, USA). Linear dye penetration was measured along the gingival floor as well as the axial wall. The ratio of linear dye penetration to the total measure of the gingival floor or axial wall was calculated and the percentage of dye penetration obtained for each specimen. Data analysis was performed by a two-way ANOVA. Tukey's post-hoc test was used for a pairwise comparison between the means when the ANOVA test was significant.

\section{Results}

The mean percentage of microleakage for the tested adhesives (ExciTE and Nano-Bond) with different interactions at the gingival floor is presented in Table 1. The microleakage (\%) of ExciTE adhesive applied in one layer (A1) at the gingival floor had the statistically significant highest mean microleakage (\%). This was followed by application of the ExciTE adhesive in two layers (A2), then Nano-Bond adhesive in one layer (B1). The statistically significant lowest mean microleakage (\%) was found with the Nano-Bond adhesive in two layers $(\mathrm{B} 2)$. There were significant differences $(\mathrm{P}<0.05)$ between study groups. Microleakage was decreased for the specimens receiving two layers.

The mean percentage of microleakage for the tested adhesives with different interactions at the axial wall is presented in Table 2. ExciTE adhesive of group A1 showed the highest microleakage while Nano-Bond adhesive of group 2 had the lowest microleakage. In a similar manner as presented in Table 2, the application of two layers of adhesive to the cavity wall reduced significantly $(\mathrm{P}<0.001)$ the microleakage $(\%)$ at axial walls. Between the specimens receiving one and two adhesive layers, there were significant differences between the gingival floor and the axial wall. The microleakage (\%) at gingival floors was higher than those at the axial wall of each specimen.

\section{Discussions}

In many dentin-bonding systems, dentin preparation is a multistage process involving three steps: 1) etching with an acidic conditioner; 2) priming with hydrophilic resin in solvent; and 3) bonding with an unfilled or lightly filled resin [23].

The major goals of using dentin-bonding systems are to enhance the bonding strength between resin and the tooth structure, increase the retention of restoration, reduce the microleakage across dentin-resin interface, and scatter the occlusal stress [24].

Marginal leakage of composite restorations may be influenced by external stress produced during chewing and internal stress produced by polymerization contraction. These stresses may compromise the material's

Table 1. Comparison between microleakage of the tested adhesives with different interactions at gingival floor.

\begin{tabular}{cccccc}
\hline Material & Adhesive Layer & Mean (\%) & SD & Rank & P-value \\
\hline \multirow{2}{*}{ ExciTE (Group A) } & one layer (A1) & 67 & 2.7 & A & \\
& two layers (A2) & 47.9 & 4.4 & B & $0.003^{*}$ \\
Nano-Bond (group B) & one layer (B1) & 24.8 & 1.7 & C & D \\
\hline
\end{tabular}

*Significant at $\mathrm{P} \leq 0.05$; means with different letters are statistically significantly different according to Tukey's post-hoc test. 
Table 2. Comparison between microleakage of the tested adhesives with different interactions at axial wall.

\begin{tabular}{|c|c|c|c|c|c|}
\hline Material & Adhesive Layer & Mean (\%) & SD & Rank & $P$-value \\
\hline \multirow{2}{*}{ ExciTE (group A) } & one layer (A1) & 34.9 & 2.5 & A & \multirow{4}{*}{$0.003^{*}$} \\
\hline & two layers (A2) & 25 & 2.4 & $\mathrm{~B}$ & \\
\hline \multirow{2}{*}{ Nano-Bond (group B) } & one layer (B1) & 16.7 & 1 & $\mathrm{C}$ & \\
\hline & two layers (B2) & 7.9 & 1.1 & $\mathrm{D}$ & \\
\hline
\end{tabular}

*Significant at $\mathrm{P} \leq 0.05$; means with different letters are statistically significantly different according to Tukey's post-hoc test.

properties, creating marginal openings and deform the tooth substrate [25] [26]. The contraction stress of composite depends upon the type and level of filler included. Generally, an increased filler level should contribute to a reduce polymerization shrinkage, since the overall polymerization shrinkage depends on the amount of polymer matrix [9]. On the other hand, the stiffness of the composite is also increased at high filler levels. The high stiffness leads to increased stress for a given contraction strain, according to Hooke's law; therefore, the composite stiffness and the amount of contraction both play important roles in the generation of stress in dental composite restorations [27].

Adhesive layer acts as an elastic intermediate layer (elastic cavity wall) between the cavity walls and the adjacent composite. This layer could resist the polymerization shrinkage stress of the resin composites and absorb the shock produced by occlusal loads and thermal cycling [19].

According to many investigators [29] [30], the uses of filled adhesive resin increases the mechanical properties and improves marginal and internal seals of composite restoration.

This study demonstrated that increasing the adhesive thickness by means of additional layering on the cavity walls should lead to an improvement of the marginal integrity and, as a consequence, may prolong the life of a restoration; however, a thick layer of low stiffness (unfilled or lightly filled) adhesive resin at the margins of restoration may lead to reduction in contraction stress and enhanced wear at this location.

The result of the present study also showed less microleakage in Nano-Bond adhesive (one and two layers). This may be contributed to increased filler levels and decreased particle sizes in Nano-Bond adhesives over the ExciTE adhesive.

The findings from this study supports many previous studies which demonstrate that gingival margins are potentially a greater source of marginal leakage in class II composite restorations compared to occlusal margins and axial walls [31]-[33]. Neme, et al. [34] have suggested that the absence of enamel at the gingival cavosurface margin of the proximal box results in low-bond strength between material and substrate. This lack of enamel requires adhesion of the restorative material to cementum/dentin, a less reliable, more complex substrate than enamel. A third hypothesis proposed for increased cervical or gingival leakage compared to that of occlusal margins or axial walls, as it relates the distance of the light source from the material at the proximal box base to the axial or occlusal surface. It has been hypothesized that the resulting higher polymerization stresses at the gingival floor cause increased dimensional changes, leading to gap formation [33]. Further laboratory studies and long-term clinical evaluations are needed before definite conclusions could be drawn.

\section{Conclusion}

In this study, Nanoparticles reinforced adhesive system shows low microleakage in compare with universal adhesive system, and application of two adhesive layers also can decrease the microleakage.

\section{References}

[1] Alster, D., Feilzer, A., de Gee, A. and Davidson, C. (1997) Polymerization Contraction Stress in Thin Resin Composite Layers as a Function of Layer Thickness. Dental Materials Journal, 13, 146-150. http://dx.doi.org/10.1016/S0109-5641(97)80115-7

[2] Uno, S. and Shimokobe, H. (1994) Contraction Stress and Marginal Adaptation of Composite Restorations in Dentinal Cavity. Dental Materials Journal, 13, 19-24. http://dx.doi.org/10.4012/dmj.13.19

[3] Cincchi, B., Bonillagent, S., Delaloye, M. and Holz, J. (1997) Volume of Internal Gap Formed under Composite Restorations in Vitro. Journal of Dentistry, 25, 305-312. http://dx.doi.org/10.1016/S0300-5712(96)00032-2 
[4] Kinomoto, Y. and Tarri, M. (1998) Photoelastic Analysis of Polymerization Contraction Stresses in Resin Composite Restoration. Journal of Dentistry, 26, 165-171. http://dx.doi.org/10.1016/S0300-5712(96)00083-8

[5] Power, J. and Sakguch, R. (2006) Craig's Restorative Dental Materials. Mosby, Inc., St Louis, 203-205.

[6] Frank, C., Miller, R., et al. (2002) Structure and Interaction of Organic/Inorganic Hybrid Nanocomposites for Microelectronic Applications. 1. MSSQ/P (MMA-co-DMAEMA) Nanocomposites. Chemistry of Materials, 14, 3676-3685. http://dx.doi.org/10.1021/cm020014z

[7] Giannelis, E. (1996) Polymer Layered Silicate Nano Composites. Advanced Materials, 8, 29-35. http://dx.doi.org/10.1002/adma.19960080104

[8] Eick, J., Byerley, T., Chappell, R., Chen, G., Bowles, C. and Chappelow, C. (1993) Properties of Expanding Soc/ Epoxy Copolymers for Dental Use in Dental Composites. Dental Materials Journal, 9, 123-127. http://dx.doi.org/10.1016/0109-5641(93)90088-8

[9] Munksgaard, E., Hansen, E. and Kato, H. (1987) Wall-to-Wall Polymerization Contraction of Composite Resins versus Filler Content. Scandinavian Journal of Dental Research, 95, 526-531. http://dx.doi.org/10.1111/j.1600-0722.1987.tb01970.x

[10] Feilzer, A., de Gee, A. and Davidson, C. (1993) Setting Stresses in Composites for Two Different Curing Modes. Dental Materials Journal, 9, 2-5. http://dx.doi.org/10.1016/0109-5641(93)90095-8

[11] Venhoven, B., de Gee, A. and Davidson, C. (1996) Light Initiation of Dental Resins: Dynamics of the Polymerization. Biomaterials, 17, 2313-2318. http://dx.doi.org/10.1016/S0142-9612(96)00074-9

[12] Condon, J. and Ferracane, J. (1998) Reduction of Composite Contraction Stress through Non-Bonded Microfiller Particles. Dental Materials Journal, 14, 256-260. http://dx.doi.org/10.1016/S0109-5641(98)00036-0

[13] Kemp-Scholte, C.M. and Davidson, C. (1988) Marginal Sealing of Curing Contraction Gaps in Class V Composite Resin Restorations. Journal of Dental Research, 67, 841-845. http://dx.doi.org/10.1177/00220345880670050901

[14] Krejci, I. and Lutz, F. (1991) Marginal Adaptation of Class V Restorations Using Different Restorative Techniques. Journal of Dentistry, 19, 24-32. http://dx.doi.org/10.1016/0300-5712(91)90032-t

[15] Davidson, C. (1994) Glass Ionomer Bases under Posterior Composites. International Journal of Esthetic Dentistry, 6, 223-424. http://dx.doi.org/10.1111/j.1708-8240.1994.tb00863.x

[16] Liberman, R., Ben-Amar, A., Herteanu, L. and Judes, H. (1997) Marginal Seal of Composite Inlays Using Different Polymerization Techniques. Journal of Oral Rehabilitation, 24, 26-29.

[17] Davidson-Kaban, S., Davidson, C., Feilzer, A., de Gee, A. and Eerdilek, N. (1997) The Effect of Curing Light Variations of Bulk Curing and Wall-to-Wall Quality of Two Types and Various Shades Resin Composites. Dental Materials Journal, 13, 344-352. http://dx.doi.org/10.1016/S0109-5641(97)80105-4

[18] Sakaguchi, R. and Berge, H. (1998) Reduced Light Energy Density Decreases Post-Gel Contraction While Maintaining Degree of Conversion in Composites. Journal of Dentistry, 26, 695-700. http://dx.doi.org/10.1016/S0300-5712(97)00048-1

[19] Kemp-Scholte, C.M. and Davidson, C. (1990) Marginal Integrity Related to Bond Strength and Strain Capacity of Composite Resin Restorative Systems. Journal of Prosthetic Dentistry, 64, 658-664. http://dx.doi.org/10.1016/0022-3913(90)90291-J

[20] Choi, K., Condon, J. and Ferracane, J. (2000) The Effects of Adhesive Thickness on Polymerization Contraction Stress of Composite. Journal of Dental Research, 79, 812-817. http://dx.doi.org/10.1177/00220345000790030501

[21] Kemp-Scholte, C.M. and Davidson, C. (1990) Complete Marginal Seal of Class V Resin Composite Restorations Effected by Increased Flexibility. Journal of Dental Research, 69, 1240-1243. http://dx.doi.org/10.1177/00220345900690060301

[22] Van Meerbeek, B., Willems, G., Celis, J., Roos, J., Braem, M., Lambrechts, P. and Vanherle, G. (1993) Assessment by Nano-Indentation of the Hardness and Elasticity of the Resin-Dentin Bonding Area. Journal of Dental Research, 72, 1434-1442. http://dx.doi.org/10.1177/00220345930720101401

[23] Swift Jr., E., Perdigao, J. and Heymann, H. (1995) Bonding to Enamel and Dentin: A Brief History and State of the Art. Quintessence International, 26, 95-110.

[24] Chen, R.-S., Liu, C.-C., Tseng, W.-Y. Jeng, J.-H. and Lin, C.-P. (2003) Cytotoxicity of Three Dentin Bonding Agents on Human Dental Pulp Cells. Journal of Dentistry, 31, 223-229. http://dx.doi.org/10.1016/S0300-5712(02)00088-X

[25] Burgess, J.O., Walker, R.S., Porche, C.J. and Rappold, A. (2002) Light-Curing-An Update. Compendium of Continuing Education in Dentistry, 23, 889-892.

[26] Lutz, F., Krejci, I., Luescher, B. and Oldenburg, T. (1986) Improved Proximal Marginal Adaptation of Class II Composite Resin Restoration by Use of Light Refolding Wedges. Quintessence International, 17, 659-664. 
[27] Braem, M., Lambrechts, P., Vanherle, G. and Davidson, C. (1987) Stiffness Increase during the Setting of Dental Composite Resins. Journal of Dental Research, 66, 1713-1716. http://dx.doi.org/10.1177/00220345870660120301

[28] Uno, S. and Finger, W. (1995) Function of the Hybrid Zone as a Stress-Absorbing Layer in Dentin Bonding. Quintessence International, 26, 733-738.

[29] Labella, R., Lambrechts, P., van Meerbeek, B. and Vanherle, G. (1999) Polymerization Shrinkage and Elasticity of Flowable Composites and Filled Adhesives. Dental Materials Journal, 15, 128-137. http://dx.doi.org/10.1016/S0109-5641(99)00022-6

[30] Wegdan, B. (2005) Effecting of Cutting Bur on the Bond Strength of Self-Etching and One Bottle Nanofilled to Enamel and Dentin. Egy Dent, 51, 1171-1179.

[31] Van Meerbeek, B., Braem, M., Lambrechts, P. and Vanherle, G. (1993) Evaluation of Two Dentin Adhesives in Cervical Lesions. Journal of Prosthetic Dentistry, 70, 308-314. http://dx.doi.org/10.1016/0022-3913(93)90213-8

[32] Linden, J. and Swift Jr., D. (1994) Microleakage of Two New Dentin Adhesives. American Journal of Dentistry, 7, 31-34.

[33] Yap, A., Stokes, A.N. and Pearson, G.J. (1996) An in Vitro Microleakage Study of a New Multi-Purpose Dental Adhesive System. Journal of Oral Rehabilitation, 23, 302-308. http://dx.doi.org/10.1111/j.1365-2842.1996.tb00857.x

[34] Neme, A., Maxson, B., Pink, F. and Aksu, M. (2002) Microleakage of Class II Packable Resin Composite Lined with Flowables: An in Vitro Study. Operative Dentistry, 27, 600-605. 